\title{
L'ÉPREUVE DE LA RÉdUCTASE \\ AU BLEU DE MÉTHYLÈNE, UN TEST D'ACTIVITÉ SIMPLE POUR LA PRÉPARATION ET L'ANALYSE DES LEVAINS DE STREPTOCOQUES LACTIQUES DANS LA FABRICATION DES FROMAGES
}

par

\author{
Joseph A. KURMANN \\ Professeur et Chef de Laboratoire. \\ Laboratoire de Biotechnologie laitière. \\ Ecole fribourgeoise de Laiterie, 1725 Grangeneuve-Fribourg (Suisse)
}

\section{I. - Introduction}

Koestler et Stüssi (1927)[1], recommandent dans le but de tester l'activité des levains de beurrerie, de faire l'épreuve de la réductase avec du bleu de méthylène, comme pour le lait. Le temps de décoloration le plus court correspond à la vitalité maximale des bactéries. Cette expérience n'a pas trouvé dans la suite l'attention méritée. Au cours du présent exposé, nous étudierons l'application de cette épreuve pour la préparation et l'analyse des levains de fromagerie.

\section{II. - Technique de l'épreuve de réductase pour les levains}

1) Matériel.

- Comme pour l'épreuve de réductase du lait ou de la crème (tubes stérilisés de 10 ou 20 , éventuellement $40 \mathrm{~cm}^{3}$ ).

- Bleu de méthylène standardisé pour l'épreuve de la réductase du lait.

2) Technique de l'épreuve.

a) On prend $10 \mathrm{~cm}^{3}$ de culture à analyser. Une certaine et identique hauteur de couche devrait toujours être respectée.

On met les cultures sur lait écrémé, de préférence, dans un tube de réductase de 20 ou $40 \mathrm{~cm}^{3}$. Lorsque le tube est trop mince, il est difficile de mélanger le bleu de méthylène avec la culture.

Les levains entreposés au frigidaire ont subi un choc de froid; de ce fait, on laisse les tubes préparés une demi-heure à 1 heure à la température du laboratoire. 
b) On ajoute du bleu de méthylène standardisé comme pour le lait $\left(0,25 \mathrm{~cm}^{3}\right.$ pour $10 \mathrm{~cm}^{3}, 0,50 \mathrm{~cm}^{3}$ pour $20 \mathrm{~cm}^{3}$ et $1 \mathrm{~cm}^{3}$ pour $40 \mathrm{~cm}^{3}$ de levain).

c) Pour le mélange, il faut agiter le moins possible. Les cultures sur lait coagulé sont réchauffées à la température d'incubation avant l'adjonction du bleu de méthylène, ce qui permet de mélanger plus facilement le bleu de méthylène. (Le mieux est, si possible, de réchauffer à $40^{\circ} \mathrm{C}$.)

d) Si la culture n'est pas déjà réchauffée, on chauffe le tube à la température d'incubation $\left(38^{\circ} \mathrm{C}\right.$ pour les levains thermophiles, $22^{\circ} \mathrm{C}$ pour le levain de beurrerie, etc.).

e) Lecture. - Il faut observer moins souvent une culture en phase de repos qu'un levain en phase de croissance.

\section{III. - Pourquoi rechercher l'activité d'une culture à l'aide de l'épreuve de la réductase?}

1) Il ne faut pas confondre l'acidité d'un levain avec son activité.

Un levain n'est pas un apport d'acide lactique, mais de bactéries actives, capables de se multiplier dans le lait, dans le caillé, etc., et de produire au moment favorable (lorsqu'un nombre suffisant de cellules est atteint), l'acidité et l'arôme recherchés [5].

Il faut ici se rappeler le décalage de l'acidification par rapport à la multiplication cellulaire (voir graphique 1). Un levain ayant atteint son acidité maximale représente une culture sur le déclin, contenant beaucoup de cellules mortes. Si on veut donc une culture très active, il faudra arrêter l'incubation lorsqu'on aura atteint le minimum de la courbe de réductase (voir le graphique 2). Dans le cas des streptocoques, dont la production d'acidité provoque une baisse du $p \mathrm{H}$ dépassant à peine le point de coagulation $(p \mathrm{H} 4,6)$, on utilise souvent, dans l'industrie, des levains non coagulés ou à peine coagulés [5].

2) La recherche en question permet de gagner du temps dans l'élaboration des levains streptococciques.

Le maximum des bactéries actives est obtenu beaucoup plus vite que l'acidité normale d'un levain (par exemple 4-6 heures plus vite, comme le graphique 2 le montre).

\section{IV. - Bases de l'épreuve et des essais préliminaires}

1) Facteurs qui influencent la vitesse de décoloration.

Les bactéries proliférant dans le lait, ont une activité réductrice, conséquence de deux phénomènes: 
GRAPHIQUE $n^{0-1}$

Courbes de croissance et d'acidification d'un ferment lactique d'après AlaIs [5]

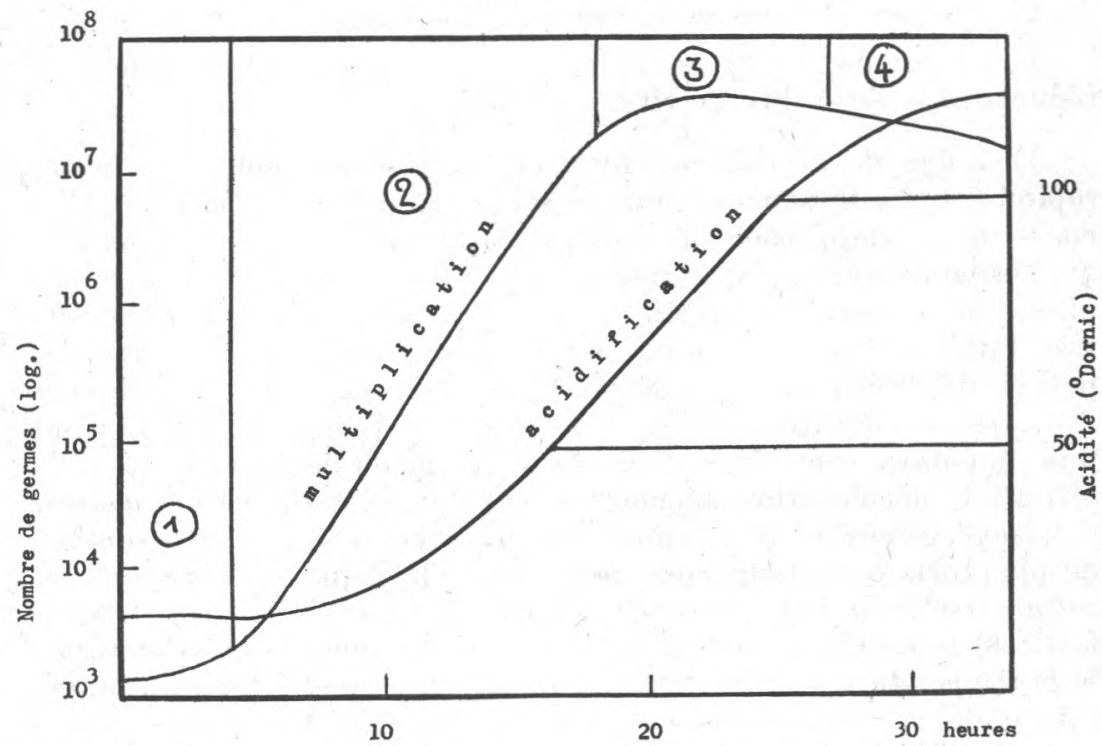

(1) Phase de latence ou d'adaptation. - (2) Phase logarithmique (croissance active). - (3) Phase maximale ou stationnaire. - (4) Phase de déclin.

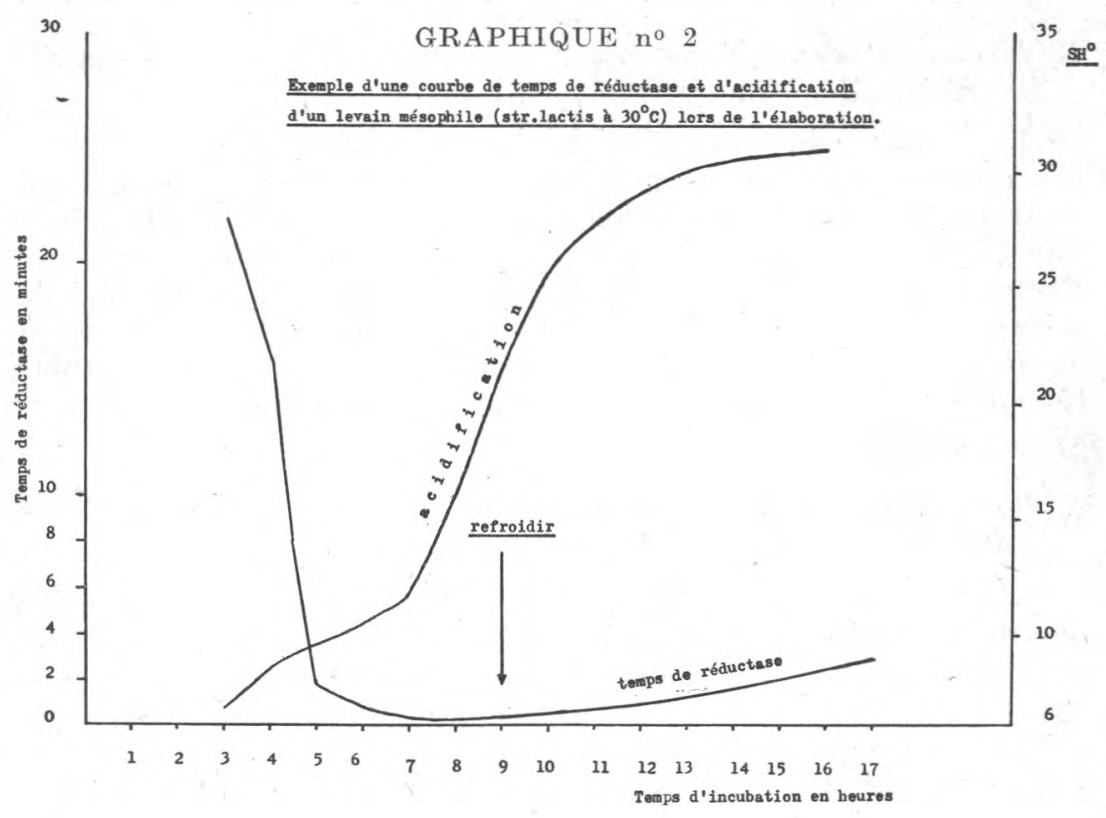


a) Absorption de l'oxygène dissous par la respiration qui provoque un abaissement du potentiel d'oxydo-réduction favorable au système réducteur naturel du lait ;

b) Système rêducteur propre aux bactéries.

Les facteurs les plus importants qui influencent l'activité réductrice, c'est-à-dire la vitesse de décoloration sont :

1) L'âge de la culture: l'espace de temps depuis le dernier repiquage, vieillissement; intoxication par les métabolites ; 2 ) $l a$ vitesse de développement: les streptocoques se multiplient plus vite que les lactobacilles; 3 ) la phase de croissance: phase de croissance, phase de croissance ralentie ou phase de repos; 4) le peuplement: très faible ou forte population; pour des cultures normales les petites différences de quantité ne jouent pas de rôle; 5) l'activité des cellules: vitalité. Pour les cultures en phase de repos, qui ont une population normale (comme c'est généralement le cas), la vitesse de décoloration dépend surtout de la vitalité ; 6) le pouvoir réducteur spécifique de l'espèce: les colibacilles sont, par exemple, de plus forts réducteurs que les bactéries lactiques; 7) le milieu de culture: selon le lait (présence de substances inhibitrices et stimulatrices) la croissance des bactéries lactiques peut être influencée; 8) la température d'incubation: l'incubation doit se faire à la température de croissance des bactéries à analyser. Pour une conservation au frigidaire, il faut réchauffer (réveiller) les levains comme indiqué ci-après ; 9) la concentration du bleu de méthylène: employer du bleu de méthylène standardisé (toujours de même concentration).

2) Traitement des levains après une conservation au frigidaire: le "réveil 》 des levains.

Les levains entreposés au frigidaire doivent être "réveillés» par réchauffement avant l'analyse. Par exemple : un levain qui se trouvait dans l'activité maximale (phase de croissance), doit être laissé une demi-heure à 1 heure à la température ambiante. Par suite d'un choc de froid, les bactéries ne reprennent pas tout de suite leur activité. Aussi les levains employés dans la fabrication du fromage de Gruyère doivent être "réveillés» ou ajoutés plus tôt au lait de fabrication (par exemple, une demi-heure à 1 heure avant coagulation).

3) Possibilité d'analyser des levains mixtes avec l'épreuve de la réductase dans la phase de repos.

L'activité des streptocoques peut être aussi recherchée dans des levains mixtes, car les lactobacilles sont des réducteurs de bleu de méthylène beaucoup plus lents que les streptocoques. Dans le cas où les streptocoques présentent une bonne activité et un nombre normal, il réduisent le bleu de méthylène avant que les bâtonnets ne soient en mesure de le faire. Par contre, dans la phase 
de croissance, les lactobacilles réduisent le bleu de méthylène aussi rapidement que les streptocoques.

4) Comparaison de la réductase des levains avec le test d'activité de Leber.

a) Test d'activité de Leber.

Leber [2], [3] propose d'ensemencer en lait écrémé stérile, $1 \mathrm{~cm}^{3}$ de la culture à analyser et d'ajouter $1 \mathrm{~cm}^{3}$ d'une solution de résazurine à 0,005 p. 100 , puis d'incuber le tube ainsi préparé à $38^{\circ} \mathrm{C}$. Après une demi-heure, on contrôle la décoloration toutes les 5 minutes. Une réduction en moins de 35 minutes indique un très bon levain; en 35-40 minutes un bon; en 50-60 minutes un satisfaisant et en plus de 60 minutes, un mauvais levain. Ce test est trop compliqué dans son application, car il demande du matériel et du lait écrémé stérile, ainsi que de la résazurine qu'on ne trouve pas toujours dans une petite exploitation fromagère.

b) Modification du test de Leber.

Par le fait que notre épreuve de la réductase des levains est effectuée sur le même milieu de culture (sans repiquage), on analyse l'état de vitalité momentané. Par contre, le test de Leber provoque une activation et montre l'état de vitalité après un passage sur du lait écrémé stérile. Lorsqu'on pratique l'essai de Leber avec du bleu de méthylène au lieu de résazurine, on constate un temps de décoloration sensiblement prolongé d'une demi-heure à 1 heure, ce qui est certainement dû au repiquage (adaptation des bactéries au lait écrémé; autre potentiel d'oxydo-réduction présent, etc.).

Pour les petites exploitations, la réductase des levains est plus simple à appliquer que le test d'activité de Leber (par la grande simplicité de la technique d'analyse et par le peu de matériel utilisé : pas de lait écrémé stérile, pas de verrerie stérile).

\section{V. - Epreuve de la réductase des levains dans la fabrication des fromages}

1) Technique simple pour préparer des levains actifs et pour déterminer l'activité maximale dans la phase de croissance lors de la préparation d'un levain.

La vitesse de réduction dans la phase de croissance dépend avant tout du nombre croissant des bactéries en multiplication et de la vitalité augmentante causée par les rajeunissements successifs. Ceux-ci provoquent une vitalité, c'est-à-dire une intensité exceptionnelle du métabolisme. 
1.1. Courbe de réduction du bleu de méthylène d'un levain dans la phase de croissance.

Lorsqu'on prépare un levain et lorsqu'on en prélève chaque heure un échantillon au cours de l'incubation pour faire le test de réductase, on constate, selon le graphique 2, d'abord une diminution progressive du temps de réduction (phase de croissance) jusqu'à un certain point (activité maximale) ou commence le temps de décoloration de plus en plus long (phase de ralentissement et arrêt de croissance). Cette application de l'épreuve de réduction montre la vitalité réactivée après un repiquage.

\subsection{Comment on procède à la préparation de la culture.}

Pour déterminer le point actif on effectue le premier contrôle après 4 heures d'incubation. A mesure que l'on se rapproche du minimum du temps de décoloration, on intensifie les contrôles. Dès que l'on voit la remontée du temps de réduction, on refroidit le levain, qui possède encore peu d'acidité. S'il est par exemple, possible de préparer le levain à 10 heures le matin, on peut le retirer à 18 heures le soir. Avec un ensemencement plus faible que d'habitude, on peut prolonger le temps d'incubation (par exemple, lors d'une incubation pendant la nuit, c'est-à-dire d'un espace de temps qui est plus long que 8 heures). Il est recommandé de déterminer en même temps non seulement le temps de réduction du bleu de méthylène mais aussi l'acidité. Toutefois l'emploi de cette technique suppose un levain sain et bien acidifiant.

Il ne faut pas retirer le levain trop tôt de l'incubation, car nous recherchons non seulement un levain très actif, mais aussi une culture riche en bactéries.

1.3 Les avantages de l'emploi de cette technique pour la préparation de levain sont:

a) L'élaboration plus rapide des levains, e'est-à-dire une économie de temps;

b) Le levain se trouve dans la phase de croissance, c'est-à-dire en plus grande activité qu'un levain préparé d'après le procédé habituel et qui se trouve déjà dans la phase de repos ou de décroissance.

c) Lors de l'inoculation au lait de fabrication on peut diminuer très fortement ou même supprimer, la phase de latence. La multiplication démarre plus vite. Ceci est particulièrement important pour une acidification rapide et l'empêchement d'un développement de germes indésirables (producteurs de gaz, etc.).

1.4. Les règles pour l'emploi des levains préparés d'après la nouvelle méthode sont:

a) $\mathrm{Si}$ possible ensemencer directement après l'incubation le levain, sans refroidissement préalable. Si cela n'est pas possible, 
"réveiller " le levain, refroidi par un séjour au frigidaire, pendant une demi-heure à une heure, comme indiqué précédemment;

b) Par suite de la très grande activité du levain, il faut éventuellement, diminuer la quantité d'ensemencement et ceci surtout lorsque se présente une tendance vers une suracidification;

c) Augmenter la quantité d'ensemencement si le levain est retiré de l'incubation un peu tôt, car il est moins riche en cellules.

1.5. Emploi de cette technique pour la sélection de souches en vue de la préparation de levain.

On éprouve les souches isolées que l'on veut employer (choisir) pour la préparation des levains. Sont sélectionnées les souches qui indiquent dans la phase de repos, le temps de réduction le plus court ou qui présentent un temps de réductase qui diminue très rapidement lors d'une inoculation en lait avec une montée d'acidification très rapide. Par contre, si le temps de réduction diminue très lentement et si l'acidification est retardée ou trop lente lors de la préparation d'un levain, cela signifie que la souche est vieille, vu qu'elle se multiplie difficilement et, ainsi, ne devrait pas être employée pour la préparation d'un levain de fromagerie.

\section{2) Exemples d'applications pratiques en fromagerie.}

\subsection{La fabrication de fromage blanc (pâtes frấches).}

Le fromage blanc doit être coagulé avant tout par l'acidité provenant des ferments lactiques. Dans le but de raccourcir le temps de fabrication et de garantir la coagulation par une forte production d'acidité, il est important d'inoculer des ferments très actifs, en phase de développement [4].

\subsection{La fabrication de pâtes molles.}

Pour la fabrication des pâtes molles, l'emploi des levains préparés selon ce procédé présente plus de garantie pour la fabrication.

2.3. La fabrication de Gruyère et d'autres pâtes dures cuites.

L'emploi de la nouvelle technique de préparation de levain est limité pour la fabrication de Gruyère à partir de lait cru :

a) Les levains employés ne sont pas des cultures pures (présures, petit-lait mûri, etc.). Les germes indésirables souvent présents en faible quantité (groupe coli-aérogènes, streptocoques fécaux, microcoques, etc.), peuvent dans certains cas, se multiplier dans un levain peu acide (tenant compte du mode de préparation actuelle dans les fromageries suisses).

b) Comme déjà mentionné, ce test ne peut être employé pour la préparation de levains mixtes de streptocoques et de lactobacilles car, par une courte incubation, la culture serait déséquilibrée en faveur des streptocoques. 
L'emploi est donc limité à des levains de streptocoques thermophiles ou de lactobacilles en culture pure (achetés d'un laboratoire et repiqués sur du lait pasteurisé). Ces levains sélectionnés, préparés selon cette technique peuvent rendre de bons services pour améliorer l'acidification, l'ouverture et la texture du fromage.

Comme on emploie pour les fromages pasteurisés uniquement des levains sélectionnés et purs, l'emploi de ce procédé serait recommandable pour ces fabrications.

\section{3) Analyse de la vitalité des levains dans la phase de repos.}

Dans la phase de repos la vitesse de réduction du bleu de méthylène est en fonction de la vitalité des cellules. Le nombre de bactéries ne joue pas de rôle, vu la teneur bactérienne qui est très haute dans un levain. Le test d'activité dans la phase de repos montre l'état de vie momentané.

\subsection{Vieillissement des levains.}

Le tableau I montre le vieillissement des levains thermophiles sur sérum (présure, petit-lait mûri). Le temps de réduction d'un levain conservé au frigidaire, est sensiblement prolongé après deux jours. Dans les levains mixtes on constate :

- Une disparition des streptocoques assez rapide après deux à quatre jours;

- Une croissance des levures;

- Une quantité appréciable des lactobacilles est présente, mais ces lactobacilles ont une activité réduite. C'est pourquoi déjà après deux à quatre jours de conservation au frigidaire d'un levain à base de petit-lait (sérum), le bleu de méthylène n'est pas décoloré.

Le vieillissement dépend de plusieurs facteurs (acidité, épuisement de certaines substances nutritives, métabolites toxiques, etc.). Le vieillissement des cultures sur du lait est moins rapide que des cultures sur du sérum (petit-lait).

3.2. Analyse des levains dans la phase de repos pour la fabrication des fromages.

Pour la fabrication de pâtes dures, cuites avec des levains mixtes qui contiennent des bâtonnets et des streptocoques, ce test est surtout un test d'activité pour les streptocoques, car ceux-ci réduisent, comme déjà mentionné, le bleu de méthylène avant que les bâtonnets soient en mesure de le faire ou de contribuer à la réduction.

Un levain mixte ne doit pas être analysé au cours de la phase de croissance du fait que les lactobacilles pourraient intervenir 


\section{TABLEAU I}

LE VIEILLISSEMENT DES LEVAINS THERMOPHILES CULTIVÉS SUR DU PETIT-LAIT (SÉRUM) ET CONSERVÉS AU FRIGIDAIRE A $+5^{\circ} \mathrm{C}$

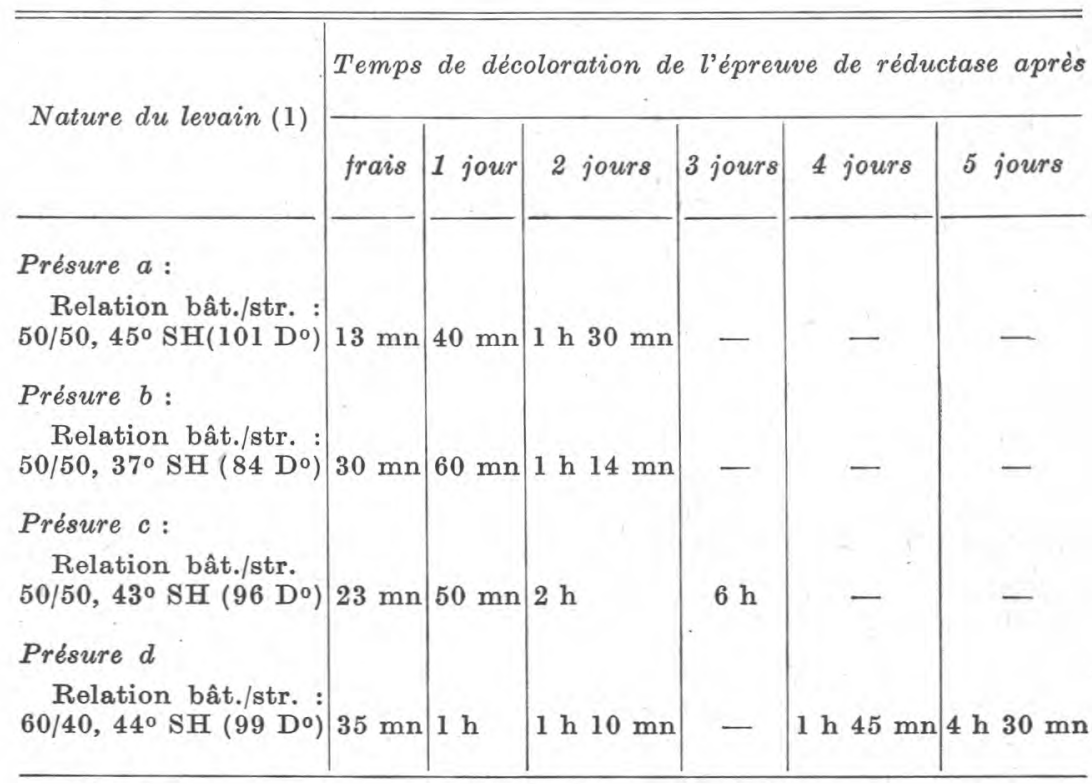

Légende

- = pas de décoloration (négatif)

bât./str. = relation ou proportion de bâtonnets et de streptocoques thermophiles.

(1) Ces levains sont employés dans la fabrication du Gruyère.

dans la décoloration. Dans la phase de croissance, les lactobacilles réduisent le bleu de méthylène aussi rapidement que les streptocoques.

L'interprétation des résultats d'analyse peut se faire de la manière suivante :

a) Lorsqu'on fait l'épreuve régulièrement, on obtient des indications sur la régularité de l'activité des bactéries d'un jour à l'autre. Pour l'interprétation des résultats, il faut tenir compte seulement des variations d'une certaine importance (par exemple plus de 15 minutes);

b) Selon les descriptions précédentes, on doit toujours tenir compte de la phase de croissance du levain (phase de croissance, croissance ralentie ou phase de repos). 


\section{TABLEAU II}

L'AOTIVITÉ DES LEVAINS COMME ELLE EST RÉVÉLÉE PAR LA VITESSE DE DÉColoration a L'ÉPREUVE DE LA RÉdUCTASE

\begin{tabular}{|c|c|c|}
\hline Activité & $\begin{array}{l}\text { Streptocoques } \\
\text { mésophiles } \\
\text { et thermophiles }\end{array}$ & Lactobacilles \\
\hline Très bonne & Avant $30 \mathrm{mn}$ & $\begin{array}{c}\text { Moins de } 1 \mathrm{~h} 30 \mathrm{mn} \\
\text { (entre } 1 \mathrm{~h} \text { et } 1 \mathrm{~h} 30 \mathrm{mn} \text { ) }\end{array}$ \\
\hline Bonne & Avant $1 \mathrm{~h}$ & Plus de $2-3 \mathrm{~h}$ \\
\hline Mauvaise & Plus de $1 \mathrm{~h} 30 \mathrm{mn}$ & Plus de $4 \mathrm{~h}$ \\
\hline
\end{tabular}

Dans le cas d'une décoloration trop tardive, il faut tout de suite chercher les causes (levain qui n'est pas assez fréquemment repiqué, dégénérescence, forte perte ou manque total de streptocoques, etc.).

c) La vitesse de réduction du bleu de méthylène est une propriété qui n'est pas directement liée au pouvoir acidifiant d'un levain. Toutefois, une diminution de la vitalité doit être considérée comme dangereuse pour l'acidification, car souvent une perte d'activité est aussi accompagnée d'une diminution du pouvoir acidifiant d'une culture.

\section{Résumé}

Il est très important de préparer des levains actifs et de déterminer leur activité maximale pendant la phase de croissance des ferments lactiques : l'épreuve de réductase, au bleu de méthylène, permet d'apprécier cette activité, ce que ne traduit pas l'acidité.

\section{Summary}

It is very important to prepare lactic starters and to determine the maximum of their activity during the periods of grouth of the lactic acid bacteria : the reductase test, with methylene blue, enables us to estimate this activity which acidity does not show. 


\section{BIBLIOGRAPHIE}

[1] Koestler, G. et StüSSI, D. - Leitfaden der Butterfabrikation p. 61-63, Éditeur Wyss Erben, Berne (1927). - Fabrication du beurre, p. 58, Éditions Wyss Erben, Berne (1944).

[2] H. Leber. - A resazurin starter activity test. Milk. Pl. Mon., 39, 40 et 42 (1950); d'après Manuale Lactis, Folge II, Klasse 2, p. 279.

[3] KASCH. - Nachweis der Wirksamkeit der Säurebakterien in der Reinkultur. Molkerei- und Käserei- Zeitung, 1, 1587, 1950. D'après Manuale Lactis, Folge II, Klasse 2, p. 279.

[4] F. Weber. - Egouttage des caillés lactiques. Thèse. Facultés des Sciences de l'Université de Nancy (1964).

[5] Ch. Alars. - Science du lait. Principes des Techniques laitières. Editions Sep., Paris (1er), 2e édit., p. 303-308, 1965.

[6] J. A. Kurmann. - Die Methylenblaureduktaseprobe, ein einfacher Aktivitätstest für die Herstellung und Untersuchung von Streptokokkensäureweckern in der Käsefabrikation. Deutsche MolkereiZeitung, 87, 324-325, 1966. 